\title{
Chemotherapy treatment decision-making experiences of older adults with cancer, their family members, oncologists and family physicians: a mixed methods study
}

\author{
Martine T. E. Puts ${ }^{1} \cdot$ Schroder Sattar $^{1} \cdot$ Kara McWatters $^{1} \cdot$ Katherine Lee $^{1} \cdot$ Michael Kulik $^{1}$. \\ Mary-Ellen MacDonald ${ }^{1}$ - Raymond Jang ${ }^{2}$ - Eitan Amir ${ }^{2}$ • Monika K. Krzyzanowska ${ }^{2}$. \\ Natasha Leighl $^{2} \cdot$ Margaret Fitch $^{1} \cdot$ Anthony M. Joshua $^{3} \cdot$ Padraig Warde $^{4}$ • \\ Ann E. Tourangeau ${ }^{1} \cdot$ Shabbir M. H. Alibhai ${ }^{5}$
}

Received: 2 August 2016 / Accepted: 26 October 2016/Published online: 9 November 2016

(C) The Author(s) 2016. This article is published with open access at Springerlink.com

\begin{abstract}
Purpose Although comorbidities, frailty, and functional impairment are common in older adults $(\mathrm{OA})$ with cancer, little is known about how these factors are considered during the treatment decision-making process by OAs, their families,
\end{abstract}

Electronic supplementary material The online version of this article (doi:10.1007/s00520-016-3476-8) contains supplementary material, which is available to authorized users.

Martine T. E. Puts

martine.puts@utoronto.ca

Schroder Sattar

Schroder.sattar@mail.utoronto.ca

Kara McWatters

kara.mcwatters@mail.utoronto.ca

Katherine Lee

katherine.lee24@gmail.com

Michael Kulik

m.kulik@mail.utoronto.ca

Mary-Ellen MacDonald

memacd21@gmail.com

Raymond Jang

Raymond.jang@uhn.ca

Eitan Amir

eitan.amir@uhn.ca

Monika K. Krzyzanowska

monika.krzyzanowksa@uhn.ca

Natasha Leighl

Natasha.leighl@uhn.ca

Margaret Fitch

marg.fitch@sunnybrook.ca and health care providers. Our aim was to better understand the treatment decision process from all these perspectives. Methods A mixed methods multi-perspective longitudinal study using semi-structured interviews and surveys with 29 OAs aged $\geq 70$ years with advanced prostate, breast,
Anthony M. Joshua

anthony.joshua@doctor.com

Padraig Warde

padraig.warde@rmp.uhn.on.ca

Ann E. Tourangeau

ann.tourangeau@utoronto.ca

Shabbir M. H. Alibhai

shabbir.alibhai@uhn.ca

Lawrence S. Bloomberg Faculty of Nursing, University of Toronto, 155 College Street suite 130, Toronto, ON M5T1P8, Canada

2 Department of Medical Oncology and Hematology, Princess Margaret Cancer Centre, University Health Network, Toronto, ON, Canada

3 Kinghorn Cancer Centre and the Garvan Institute of Medical Research, University of Newsouth Wales, Sydney, Australia

4 Department of Radiation Oncology, Princess Margaret Cancer Centre, University Health Network, Toronto, ON, Canada

5 Department of Medicine and Institute of Health Policy, Management, and Evaluation, University Health Network and University of Toronto, Toronto, ON, Canada 
colorectal, or lung cancer, 24 of their family members, 13 oncologists, and 15 family physicians was conducted. The sample was stratified on age (70-79 and 80+). All interviews were analyzed using thematic analysis.

Results There was no difference in the treatment decisionmaking experience based on age. Most OAs felt that they should have the final say in the treatment decision, but strongly valued their oncologists' opinion. "Trust in my oncologist" and "chemotherapy as the last resort to prolong life" were the most important reasons to accept treatment. Families indicated a need to improve communication between them, the patient and the specialist, particularly around goals of treatment. Comorbidity and potential side-effects did not play a major role in the treatment decision-making for patients, families, or oncologists. Family physicians reported no involvement in decisions but desired to be more involved.

Conclusion This first study using multiple perspectives showed neither frailty nor comorbidity played a role in the treatment decision-making process. Efforts to improve communication were identified as an opportunity that may enhance quality of care.

Condensed abstract In a mixed methods study multiple perspective study with older adults with cancer, their family members, their oncologist and their family physician we explored the treatment decision making process and found that most older adults were satisfied with their decision. Comorbidity, functional status and frailty did not impact the older adult's or their family members' decision.

Keywords Decision making - Aged · Functional status · Comorbidity $\cdot$ Mixed methods study $\cdot$ Geriatric oncology

\section{Introduction}

Older adults are heterogeneous in terms of health, functional, psychological, social, and economic status [1]. With increasing age the levels of frailty increase and there is decline in physiologic function that influences both the risks and benefits of treatment [2]. Studies show that under-treatment in older adults with cancer is common and is related to age and comorbidities [3-8]. Evidence also shows greater variation in treatments offered by oncologists [9-12] to older adults with declining health, suggesting difficulty in identifying and recommending the most appropriate treatment for this population.

A previous systematic review of cancer treatment decisionmaking showed that few studies have focused on older adults aged 70+ [13]. Furthermore, although recent studies explored factors influencing the treatment decision-making process from the perspectives of older adults with cancer [14, 15], none explored the influence of frailty, comorbidity, or functional status while they have been shown to be associated with treatment tolerability and outcomes [16-18]. In addition, few studies explored support needed to enhance the quality of the treatment decision-making process for older adults, their family members, oncologists and family physicians. The aims of this study were to examine the treatment decision-making process from all four perspectives, as well to explore how comorbidity, frailty, and functional status influenced the decision-making process.

\section{Patients and methods}

\section{Study design}

We conducted a mixed method multi-perspective longitudinal study [19-21]. Older adults with cancer were invited to complete two semi-structured interviews and surveys: one after the treatment decision had been made [up to six months after the decision] and one 3-6 months later to allow examination of changes over time. The other participants (family members, oncologist and family physician) were invited to participate in one semi-structured interview. Multi-perspective interviews were used as they can provide complementary and contradictory perspectives [22].

The study was approved by each participating institution's research ethics board. All participants provided written informed consent.

\section{Study participants}

Older adults with cancer aged $\geq 70$ with advanced breast, prostate, colorectal, and lung cancer and who made a treatment decision about palliative chemotherapy in the previous six months at the Princess Margaret Cancer Centre, University Health Network or the Odette Cancer Centre, Sunnybrook Health Sciences Centre, both in Toronto Canada between July 2014 and August 2015 were eligible.

Purposeful sampling was used to maximize opportunities to develop concepts and identify relationships among concepts [23]. The process of data collection and analysis was cyclical to allow time for reflection and opportunity to refine questions.

The older adult sample was stratified by age (70-79 and $80+$ ) to ensure adequate representation from the oldest adults, as treatment benefits and risks differ with increasing comorbidity, frailty and age. The number of participants was guided by data saturation in each stratum.

Sixty-seven older adults were invited to participate; 38 agreed and 29 declined. The most common reason for decline was that the older adult was not interested. Six patients did not complete the first interview. While 6 agreed to participate they were not interviewed for various reasons. Reasons included: change of mind $(n=1)$, family member disapproval $(n=1)$, or 
declining health $(n=4)$. Three patients slightly younger than 70 were recruited at the Odette Cancer Centre by mistake; they were retained as their experiences were similar to other participant's experiences.

At the end of the first older adult interview the other participants were identified and recruited subsequently. All but one invited family member participated. Fifteen family physicians agreed to participate, seven refused and the other older adults did not have one. Thirteen oncologists participated and three declined. Eleven older adults passed away and two withdrew before the second interview.

\section{Interviews}

Semi-structured interviews were conducted using topic guides (see Supplemental information file 1). The interviews included questions about health and treatment recommendations, factors that influenced the treatment decision-making process, information needs, support needs, and the influence of comorbidities and functional status on the treatment decision-making process. Twentytwo participants were interviewed by the telephone as per the patients' wishes; six were interviewed at home and four were interviewed in the cancer centers. All family members and family physicians were interviewed by telephone. The oncologists were interviewed in their office. All interviews were audio-recorded and transcribed verbatim and field notes were written to provide context for the interview. Interviews were conducted by the PI and trained nursing students. Most interviews lasted between 15 and $60 \mathrm{~min}$.

Member checking was used to validate our findings [23] by sending all participants the summary of their interview findings with a return envelope for corrections.

\section{Survey and chart data}

Older adults were asked to complete a survey after both interviews to obtain social demographic information, and information on health, frailty (using the Vulnerable Elder Survey (VES) - 13 items [24]), and the decision making (the 1 item Control Preferences Scale [25] to assess decisional preferences and Satisfaction with Decision Scale [26] which is a sum of the six items and ranges $6-30$ with higher scores indicating more satisfaction). Two initial and seven follow-up surveys were missing for reasons including patients' death and not receiving surveys back.

Cancer diagnosis, comorbid conditions and the Eastern Cooperative Oncology Group performance status [27] closest to the interview date were abstracted from the chart.

\section{Data analysis}

Interviews were transcribed verbatim and analyzed with support of NVivo v.10 using a thematic analysis approach [28]. The PI and research assistant read the transcripts to explore emerging themes. We used constant comparison to identify the themes and data from each perspective. Initially data from each perspective was analyzed separately and in the next step as case studies around the older adult [19]. The findings were discussed with the research team to reach peer consensus.

Descriptive statistics were used to summarize survey results and describe the characteristics of older adults. The VES-13 was used to categorize patients into frail (score of $\geq 3$ ) and non-frail to explore whether the treatment decision-making process was different.

\section{Results}

Twenty-three men and nine women participated (see Table 1 and Supplemental information Table 1). Eighteen were aged $70-79,11$ were aged 80+ and 3 were aged 63-69. Four older adults had breast cancer, 11 had prostate cancer, six had colorectal cancer, and 11 had lung cancer. Seven patients lived alone. All participants were satisfied with their treatment decision-making process using the Satisfaction with Decision-making scale (mean 25.4 (SD 2.7) for age 70-79 and mean 25.7 (SD 4.5) age 80+). There were 9 persons in the "young old" group frail (VES-13 score $\geq 3$ ). In the "old old" group 6 were frail. Of the 27 family members who participated in this study, 14 were children, 10 were spouses and 1 was a friend who had become the caregiver. Female participants had more often a child as their caregiver (7/9 participants) compared to the male participants who had more spouses as caregivers $(8 / 23)$.

\section{Themes according to participant group}

Themes per participant group are reported in Supplemental information Table 2 with citations and are summarized below.

\section{Older adults}

All but four patients accepted the recommended treatment. There were no differences in the treatment decision-making process based on age, frailty or comorbidities. The following three themes to describe the older adults' treatment decisionmaking processes emerged:

\section{Relationship with the oncologist}

The most common reason for accepting chemotherapy was based on their relationship and their trust in the oncologist as 
Table 1 Study participants characteristics

\begin{tabular}{lcc}
\hline Characteristic & Young old: $\boldsymbol{n}=\mathbf{2 1}$ & $\begin{array}{l}\text { Aged 80 years } \\
\text { and older } \boldsymbol{n}=\mathbf{1 1}\end{array}$ \\
\hline Sex & & \\
$\quad$ Woman & $5(24 \%)$ & $4(36 \%)$ \\
$\quad$ Man & $16(76 \%)$ & $7(64 \%)$ \\
$\quad$ Living alone & $5(24 \%)$ & $3(27 \%)$ \\
Cancer type & & \\
$\quad$ Breast & $3(14 \%)$ & $1(9 \%)$ \\
Colorectal & $4(19 \%)$ & $1(9 \%)$ \\
$\quad$ Prostate & $7(33 \%)$ & $4(36 \%)$ \\
$\quad$ Lung & $7(33 \%)$ & $5(45 \%)$ \\
Interview with family member & $16(76 \%)$ & $9(82 \%)$ \\
Interview with oncologist & $18(86 \%)$ & $10(91 \%)$ \\
Interview with family physician & $12(57.1 \%)$ & $6(55 \%)$ \\
\hline
\end{tabular}

expert to recommend the best treatment. The older adults felt that their oncologists were generally supportive and took the time to explain things to them and answer their questions. However, about a third of older adults felt that they were often being rushed by their oncologist and the appointments were too short to allow them to express their concerns and ask their questions. One-third of the patients sought advice from their family physicians regarding their disease and treatment.

\section{Perceived benefits and harms/discomfort}

There were many older adults that accepted the oncologists' recommended chemotherapy as they saw chemotherapy as the last resort to prolong life. Others accepted chemotherapy to maintain quality of life. Comorbidity and functional status did not play any role in the treatment decision-making process for most patients despite some older adults reporting having several other diseases. Travel to the hospital did influence decisions of older adults who were dependent on family.

\section{Treatment experiences of important others/family influences}

Four patients described how others' positive chemotherapy experiences made them accept chemotherapy, reasoning that if it worked for others and they were doing well it made the decision easier to accept it. Two accepted chemotherapy because their family told them to accept and one patient who initially did not want chemotherapy changed her mind after her family was upset and wanted her to try it.

\section{Family members}

The following themes emerged from interviews with family members:

\section{Trust in the oncologist}

The family members trusted the oncologist to give the best treatment recommendations based on his/her expertise. They often searched online for more information. They were unsatisfied with the opportunities for telephone contact because of the miscommunications or contradicting information with regard to follow-up care.

\section{Perceived benefits and harms}

Family members wanted treatment to prolong life and they indicated that they were not always clear on what the intended outcome of the treatment was. They mentioned that they would like more information about the actual goal, whether that was reduction in a specific symptom or stabilizing the disease etc. However, several family members did not feel comfortable asking explicit questions about prognosis.

\section{Family physicians}

\section{Lack of involvement}

Family physicians reported not being involved in the treatment decision-making process and some voiced that they would like to be more involved in the care of their patients and be involved earlier than only being included at the endof-life stage. Family physicians reported that patients usually did not come back for advice regarding treatment. However, those older adults that did come to see them often lacked the details on the treatment that was suggested and thus they could not provide support with the treatment decision-making process.

\section{Oncologists}

"easy decision"

The majority of the oncologists stated that coming up with their treatment recommendation was easy and that most patients did not have a hard time making a decision. Several oncologists stated that they do take functional status (performance status) into consideration when assessing for treatment suitability. Some oncologists used dose-reduction due to patients' age. The challenges of formulating treatment was balancing risks and benefits of treatment and to help patients, 
Table 2 Summary table of the influence of functional status, frailty and comorbidity on the treatment decision-making process

\begin{tabular}{|c|c|c|c|c|}
\hline Domains & Older Adult & Family member & Cancer Specialist & Family physician \\
\hline Functional status & $\begin{array}{l}\text { Prolonging life is } \\
\text { most important, for } \\
\text { others maintaining } \\
\text { quality of life is } \\
\text { important }\end{array}$ & $\begin{array}{l}\text { Prolonging life is } \\
\text { most important }\end{array}$ & $\begin{array}{l}\text { Most patients were fit, } \\
\text { performance status } \\
\text { is taken into account }\end{array}$ & Not involved \\
\hline Comorbidity & $\begin{array}{l}\text { Other health conditions } \\
\text { do not play a role } \\
\text { in the chemotherapy } \\
\text { decision }\end{array}$ & $\begin{array}{l}\text { Other health conditions } \\
\text { do not play a role in } \\
\text { the chemotherapy } \\
\text { decision }\end{array}$ & $\begin{array}{l}\text { Comorbidity is taken into } \\
\text { account but most patients } \\
\text { were fit so it did not play } \\
\text { an important role }\end{array}$ & $\begin{array}{l}\text { Not contacted for the } \\
\text { patient's medical } \\
\text { history, some feel } \\
\text { the patient's comorbidity } \\
\text { is underappreciated } \\
\text { by oncologists }\end{array}$ \\
\hline Frailty & Not mentioned by patients & $\begin{array}{l}\text { Not mentioned by family } \\
\text { members (but they do } \\
\text { describe weakened states } \\
\text { after the start of } \\
\text { chemotherapy) }\end{array}$ & $\begin{array}{l}\text { Not mentioned by all except } \\
\text { one }\end{array}$ & $\begin{array}{l}\text { Not contacted for any } \\
\text { information with regard } \\
\text { to health and functional } \\
\text { status }\end{array}$ \\
\hline
\end{tabular}

particularly for those who were eager for treatment, understand the importance of the risk-benefit balance.

\section{Comparison of the four perspectives}

Several discrepancies between the four participant groups were noted (see Table 2 and Supplemental information Table 3) and are described below.

\section{Different perspectives on frailty and function}

Older adults stated they were in good shape, and reported no major concerns other than fatigue. Older adults did not mention frailty. No family member mentioned frailty; although they did often describe a weakened state after starting chemotherapy. Only one oncologist stated that the decision about what treatment to recommend was challenging due to the patient's frail status.

\section{Different perspectives on comorbidity}

Most patients stated they had good health, and denied having any major comorbidities. Those with comorbidities mentioned they were being treated for them and thus comorbidity played no role in their treatment decisionmaking process. Family members also indicated that comorbidities played no role in the treatment decisionmaking process. In contrast, some family physicians stated that comorbidities were often not sufficiently taken into account in the cancer treatment decision-making process. Oncologists spoke of most patients as fit patients and therefore comorbidity had no influence on the treatment decision-making process. Although several patients denied having any comorbidities and stated they had good health, their family physician described these same patients' as having multiple comorbidities and health issues. Oncologists did not always mention these multiple comorbidities. Despite oncologists and patients reporting good health there was a substantial proportion who were classified as frail on the VES-13, which was only due to age alone (aged $85+$ ) in two patients.

\section{Differences in who made the decision}

Almost all patients stated that they made the treatment decision themselves. However, they also talked about 'leaving it up to the specialist'. Of note, most older adults indicated on the Control Preferences Scale a desire to make their own decision after seriously considering their doctor's opinion. Oncologists indicated that patients made their own decisions. Lastly, differences in perspectives were observed between family members. Spouses of patients spoke of "his/her decision" because it is "his/her life" or "his/her body". These decisions were usually made in the moment. Contrastingly, children spoke of "we decisions", and they took time to think and discuss the treatments recommended at home. Children were often more actively involved in finding additional information about the treatment decision to be made than spouses.

\section{(Mis)communication}

Several older adults and family members voiced their dissatisfaction with their family physician due to delays in diagnosis/wrong diagnoses. However, these family physicians did not seem to be aware of this dissatisfaction. Some older adults accepted chemotherapy to 'get better' and 'to cure 
Table 3 Participants' Suggestions for Improvement

\begin{tabular}{|c|c|c|c|}
\hline Patient & Family member & Oncologist & Family physician \\
\hline $\begin{array}{l}\text { - More discussion about financial } \\
\text { support in terms of travel costs } \\
\text { during treatment. }\end{array}$ & $\begin{array}{l}\text { - More written, understandable } \\
\text { information about the } \\
\text { recommended treatment }\end{array}$ & - More social work access & $\begin{array}{l}\text { - Improvement on transportation } \\
\text { and home care }\end{array}$ \\
\hline $\begin{array}{l}\text { Heads up if next appointment will } \\
\text { involve decision-making so they } \\
\text { can prepare and bring somebody; } \\
\text { also, more time allocated for those } \\
\text { appointments so that all questions } \\
\text { can be asked }\end{array}$ & $\begin{array}{l}\text { - More resources/directions on where } \\
\text { to go online to find reliable } \\
\text { information (e.g. provide a list } \\
\text { of trustworthy websites). }\end{array}$ & $\begin{array}{l}\text { - More support for patient } \\
\text { assessment - no time in } \\
\text { clinic to perform } \\
\text { geriatric assessment (GA) }\end{array}$ & $\begin{array}{l}\text { - More timely information about } \\
\text { diagnosis, treatment (including } \\
\text { actual drug and how it works), } \\
\text { what side effects are and } \\
\text { WHEN do they start }\end{array}$ \\
\hline - More clarification of medication terms & $\begin{array}{l}\text { - More clarification with regard to } \\
\text { medical terminology }\end{array}$ & $\begin{array}{l}\text { - Get family physicians } \\
\text { involved }\end{array}$ & $\begin{array}{l}\text { - Opportunity to participate in } \\
\text { discussion regarding end-of- } \\
\text { life care }\end{array}$ \\
\hline - Listen to the patients & $\begin{array}{l}\text { - Take time to sit down and listen } \\
\text { to patients }\end{array}$ & $\begin{array}{l}\text { - Each patient should be } \\
\text { assigned a care navigator }\end{array}$ & $\begin{array}{l}\text { - To be informed earlier if patients } \\
\text { have no more treatment } \\
\text { options; be informed by } \\
\text { oncologist before hearing it } \\
\text { from the patient }\end{array}$ \\
\hline $\begin{array}{l}\text { - Nurses need to make more } \\
\text { conversations }\end{array}$ & $\begin{array}{l}\text { - More information on what } \\
\text { treatment } \\
\text { success means }\end{array}$ & & $\begin{array}{l}\text { - Be more informed about What } \\
\text { treatment goal is }\end{array}$ \\
\hline $\begin{array}{l}\text { - Inform other patients that nurses are } \\
\text { a source of support during TDMP }\end{array}$ & $\begin{array}{l}\text { - Clinics should avoid appointment } \\
\text { changes on short notice as it is } \\
\text { very difficult for caregivers to } \\
\text { arrange for time off work to } \\
\text { come to appointments }\end{array}$ & & $\begin{array}{l}\text { - A paid patient } \\
\text { navigator/manager } \\
\text { (somebody with healthcare } \\
\text { training such as a retired } \\
\text { professional) should be } \\
\text { assigned } \\
\text { to each patient to help him/her } \\
\text { navigate the system }\end{array}$ \\
\hline $\begin{array}{l}\text { - Each patient should be assigned a } \\
\text { patient care coordinator/manager/ } \\
\text { navigator to help navigate the large, } \\
\text { confusing system, which could be } \\
\text { especially frightening for those who } \\
\text { do not speak English. }\end{array}$ & $\begin{array}{l}\text { - For patients with brain metastases, } \\
\text { more consideration should be } \\
\text { given in terms of who information } \\
\text { is given to (if patient is confused) }\end{array}$ & & $\begin{array}{l}\text { - Oncologists need to understand } \\
\text { psychosocial background and } \\
\text { patient wishes }\end{array}$ \\
\hline $\begin{array}{l}\text { - More continuity in staff support } \\
\text { (i.e. same nurse during each visit) }\end{array}$ & $\begin{array}{l}\text { - Appointment reminders should be } \\
\text { emailed to designated caregivers } \\
\text { rather than to patients }\end{array}$ & & $\begin{array}{l}\text { - Oncologists should discuss more } \\
\text { openly treatment goals - } \\
\text { advanced care planning }\end{array}$ \\
\hline $\begin{array}{l}\text { - Efforts should be made to ensure } \\
\text { that phone numbers given to call for } \\
\text { questions are helpful. Be sure there is } \\
\text { someone to ask when questions arise }\end{array}$ & $\begin{array}{l}\text { - Space and designated room in } \\
\text { hospital for peer support } \\
\text { (for patients and families). } \\
\text { - Better communication and } \\
\text { coordination to prevent } \\
\text { contradicting treatment } \\
\text { possibilities given to patients } \\
\text { (fellows vs. oncologists) to } \\
\text { avoid raising patients' hopes } \\
\text { only to be disappointed later } \\
\text { when told something different. }\end{array}$ & & for patients \\
\hline
\end{tabular}

cancer' while these patients were receiving chemotherapy with palliative intent.

Many oncologists felt that it was not useful to contact family physicians as they are not experienced and cannot add value to the discussion or are not interested. Conversely, some family physicians felt that they were not given the opportunity to get involved in the treatment decision-making process nor included in the discussion regarding patients' treatment goal, prognosis, and transition from active treatment to palliative/ end-of-life care.

\section{Suggestions for improvement}

While most older adults were satisfied and had few suggestions, several family members (particularly children) and 
family physicians had several suggestions to improve care. These are summarized in Table 3.

\section{Changes over time}

Half of the older adults were still on the same treatment regimen at the time of their second interview. Most of them were feeling better and noticed an improvement in functional status. All of them were satisfied with the information they received to support their treatment decision-making process, including the two patients who had to stop chemotherapy due to side effects. All but one patient stated they would have made the same decision if they were to go through the same treatment decision again.

\section{Discussion}

We interviewed a series of older adults with advanced cancer along with their families, oncologists and family physicians to examine the treatment decision-making process and factors influencing it. Most accepted the treatment recommended by their oncologist based on trust. Surprisingly, comorbidity and functional status were not important factors influencing treatment decisions from the perspective of patients, families or oncologists in this study.

Our findings that most older adults and families accepted the treatment recommendation by the oncologist based on trust is in agreement with earlier studies [13]. The patient's choice to follow the oncologists' suggestions and place their trust in them aligns with the notion that there may exist a natural developmental tendency for older adults to desire less responsibility for medical decisions and to rely on the expertise of others. This is in agreement with the Socio-emotional Selectivity Theory (i.e. the selection and pursuit of goals change as one ages and time becomes limited [29]). As a result, interest in knowledge pursuit decreases, and older adults become less interested in problem-solving, planning, or information. However, this may change with increasing use of information technology (e.g. the Internet). Furthermore, only four patients declined the proposed treatment. This may be due to the two recruitment sites; both cancer centers are the largest comprehensive cancer centers in Canada and they attract patients that want a certain treatment not available or not offered in smaller hospitals as well as patients who want to be treated aggressively and therefore, are willing to travel to these famous cancer centers.

The decision to initiate chemotherapy in older adults is an important task facing oncologists and entails considering a number of factors including life expectancy, treatment benefit and tolerance, and availability of social support, along with considerations to minimize treatment toxicity [30-32]. Recently the use of geriatric assessment has been recommended to help make chemotherapy treatment decisions in older adults $[16,33]$ by assessing the level of frailty and functional impairments as well as determining remaining life expectancy in the context of their other health conditions. Frailty was not a common theme brought up by oncologists. Many oncologists state that their patients were "fit enough" to undergo chemotherapy. However, research has shown that oncologists may overestimate the level of fitness of patients and that a frailty/geriatric assessment may give a better idea of the level of functioning of the patient [34] and none of the oncologists mentioned using any geriatric oncology guidelines or geriatric assessment tools to inform their treatment recommendation.

Older adults often have a long relationship with their family physicians whom they trust and who was often the health care professional investigating the symptoms leading to the cancer diagnosis and after referral there was a gap in communication. Improving the communication between the oncologist and family physician could improve quality of care at every stage of the disease and treatment as well as smooth transition for patients as they approach end-of-life [35, 36].

A strength of this study is our multi-perspective qualitative design and the first to explore the impact of frailty, comorbidity and function from each perspective. Results showed the advantages of using multiple perspectives as highlighted in the differences and discrepancies as well as agreements observed. However, generalizability of study findings must be made with caution. They were recruited at two highly specialized cancer centers that may attract different patients compared to other hospitals. Moreover, those who died or were too sick to participate in the second interview might have had different perspectives in terms of their satisfaction with the treatment decision-making process.

In conclusion, patients and family members were largely satisfied with their treatment decision-making process. Efforts to improve communication between oncologists and family physicians and between oncologists and patient and their families are needed to enhance the quality of the treatment decision-making process.

Acknowledgments The authors would like to thank all staff at the Princess Margaret Cancer Centre and the Odette Cancer Centre for their support.

\section{Compliance with ethical standards}

Funding This study was funded by an Innovation grant (grant \# 702,050) from the Canadian Cancer Society Research Institute. Dr. Puts is supported by a Canadian Institutes of Health Research New Investigator Award.

\section{Conflict of interest None.}

Open Access This article is distributed under the terms of the Creative Commons Attribution-NonCommercial 4.0 International License (http:// creativecommons.org/licenses/by-nc/4.0/), which permits any noncommercial use, distribution, and reproduction in any medium, provided you give appropriate credit to the original author(s) and the source, provide a link to the Creative Commons license, and indicate if changes were made. 


\section{References}

1. Santoni G, Angleman S, Welmer AK, Mangialasche F, Marengoni A, Fratiglioni L (2015) Age-related variation in health status after age 60. PLoS One 10(3):e0120077

2. Bergman H, Ferrucci L, Guralnik J et al (2007) Frailty: an emerging research and clinical paradigm-issues and controversies. J Gerontol A Biol Sci Med Sci 62(7):731-737

3. Landrum MB, Keating NL, Lamont EB, Bozeman SR, McNeil BJ (2012) Reasons for underuse of recommended therapies for colorectal and lung cancer in the veterans health administration. Cancer 118(13):3345-3355

4. Monroe MM, Myers JN, Kupferman ME (2013) Undertreatment of thick head and neck melanomas: an age-based analysis. Ann Surg Oncol 20(13):4362-4369

5. Noon AP, Albertsen PC, Thomas F, Rosario DJ, Catto JW (2013) Competing mortality in patients diagnosed with bladder cancer: evidence of undertreatment in the elderly and female patients. $\mathrm{Br}$ J Cancer 108(7):1534-1540

6. Shumway DA, Hamstra DA (2015) Ageism in the undertreatment of high-risk prostate cancer: how long will clinical practice patterns resist the weight of evidence? J Clin Oncol 33(7):676-678

7. Weiss A, Noorbaksh A, Tokin C, Chang D, Blair SL (2013) Hormone receptor-negative breast cancer: undertreatment of patients over 80. Ann Surg Oncol 20(10):3274-3278

8. Lee L, Cheung WY, Atkinson E, Krzyzanowska MK (2011) Impact of comorbidity on chemotherapy use and outcomes in solid tumors: a systematic review. J Clin Oncol 29(1):106-117

9. Hurria A, Naeim A, Elkin E et al (2007) Adjuvant treatment recommendations in older women with breast cancer: a survey of oncologists. Crit Rev Oncol Hematol 61(3):255-260

10. Wan-Chow-Wah D, Monette J, Monette M et al (2011) Difficulties in decision making regarding chemotherapy for older cancer patients: a census of cancer physicians. Crit Rev Oncol Hematol 78(1):45-58

11. Puts MT, Girre V, Monette J et al (2010) Clinical experience of cancer specialists and geriatricians involved in cancer care of older patients: a qualitative study. Crit Rev Oncol Hematol 74(2):87-96

12. Krzyzanowska MK, Regan MM, Powell M, Earle CC, Weeks JC (2009) Impact of patient age and comorbidity on surgeon versus oncologist preferences for adjuvant chemotherapy for stage III colon cancer. J Am Coll Surg 208(2):202-209

13. Puts MT, Tapscott B, Fitch M et al (2015) A systematic review of factors influencing older adults' decision to accept or decline cancer treatment. Cancer Treat Rev 41(2):197-215

14. Lifford KJ, Witt J, Burton M et al (2015) Understanding older women's decision making and coping in the context of breast cancer treatment. BMC Med Inform Decis Mak 15:45

15. Morgan JL, Burton M, Collins K et al (2015) The balance of clinician and patient input into treatment decision-making in older women with operable breast cancer. Psychooncology 24(12):1761-1766

16. Wildiers H, Heeren P, Puts M et al (2014) International Society of Geriatric Oncology consensus on geriatric assessment in older patients with cancer. J Clin Oncol 32(24):2595-2603
17. Puts MT, Hardt J, Monette J, Girre V, Springall E, Alibhai SM (2012) Use of geriatric assessment for older adults in the oncology setting: a systematic review. J Natl Cancer Inst 104(15):1134-1164

18. Puts MT, Santos B, Hardt J et al (2014) An update on a systematic review of the use of geriatric assessment for older adults in oncology. Ann Oncol 25(2):307-315

19. Kendall M, Murray SA, Carduff E et al (2009) Use of multiperspective qualitative interviews to understand patients' and carers' beliefs, experiences, and needs. BMJ 339:b4122

20. Murray SA, Kendall M, Carduff E et al (2009) Use of serial qualitative interviews to understand patients' evolving experiences and needs. BMJ 339:b3702

21. Creswell JW, Plano Clarke VL (2010) Designing and conducting mixed methods research, 2nd edn. Sage Publications, Thousand Oaks

22. Eisikovits Z, Koren C (2010) Approaches to and outcomes of dyadic interview analysis. Qual Health Res 20(12):1642-1655

23. Patton MQ (1990) Qualitative evaluation and research methods. Sage Publications, Newbury Park CA

24. Saliba D, Elliott M, Rubenstein LZ et al (2001) The vulnerable elders survey: a tool for identifying vulnerable older people in the community. J Am Geriatr Soc 49(12):1691-1699

25. Degner LF, Sloan JA, Venkatesh P (1997) The control preferences scale. Can J Nurs Res 29(3):21-43

26. Holmes-Rovner M, Kroll J, Schmitt N et al (1996) Patient satisfaction with health care decisions: the satisfaction with decision scale. Med Decis Mak 16(1):58-64

27. Oken MM, Creech RH, Tormey DC et al (1982) Toxicity and response criteria of the eastern cooperative oncology group. Am J Clin Oncol 5(6):649-655

28. Pope C, Ziebland S, Mays N (2000) Qualitative research in health care. Analysing qualitative data. BMJ 320(7227):114-116

29. Carstensen LL, Isaacowitz DM, Charles ST (1999) Taking time seriously. A theory of socioemotional selectivity. Am Psychol 54(3):165-181

30. Hurria A, Wildes T, Baumgartner J, et al. (2015) Older Adult Oncology. National Comprehensive Cancer Network

31. Balducci L, Colloca G, Cesari M, Gambassi G (2010) Assessment and treatment of elderly patients with cancer. Surg Oncol 19(3): $117-123$

32. Extermann M (2011) Basic assessment of the older cancer patient. Curr Treat Options in Oncol 12(3):276-285

33. Pallis AG, Fortpied C, Wedding U et al (2010) EORTC elderly task force position paper: approach to the older cancer patient. Eur J Cancer 46(9): 1502-1513

34. Wedding U, Kodding D, Pientka L, Steinmetz HT, Schmitz S (2007) Physicians' judgement and comprehensive geriatric assessment (CGA) select different patients as fit for chemotherapy. Crit Rev Oncol Hematol 64(1):1-9

35. Sada YH, Street RL Jr, Singh H, Shada RE, Naik AD (2011) Primary care and communication in shared cancer care: a qualitative study. Am J Manag Care 17(4):259-265

36. Nekhlyudov L, Latosinsky S (2010) The interface of primary and oncology specialty care: from symptoms to diagnosis. J Natl Cancer Inst Monogr 2010(40):11-17 